Please refer to the definitive version of this article when citing:

Lund, N.F., Scarles, C. \& Cohen, S.A. (2019). The brand value continuum: countering codestruction of destination branding in social media through storytelling. Journal of Travel Research (In press).

\title{
The brand value continuum: Countering co-destruction of destination branding in social media through storytelling
}

\begin{abstract}
Social media users are increasingly harming destination brands through their posts. This paper examines how to counter brand co-destruction in social media through the application of storytelling practices. Based on a netnography of TripAdvisor and Facebook, combined with a case study of the Danish destination management organization (DMO) VisitDenmark, the paper investigates the prospective ways in which social media users co-destroy the DMO's brand. We demonstrate how value creation is a fluid process generated along a 'brand value continuum', as complex interplays between co-creation and co-destruction manifest through user generated content. The paper provides recommendations on how DMOs can counter codestruction by using storytelling to influence perceptions and set agendas for user conversations that stimulate brand co-creation.
\end{abstract}

Keywords: branding, co-creation, co-destruction, social media, storytelling, destination management

\section{Introduction}

This paper proposes that storytelling in social media can be an effective instrument in enhancing co-creation and countering co-destruction of destination brands. Travelers are increasingly sharing their experiences on social media which affect tourists' perceptions and decision making ( $\mathrm{Liu}, \mathrm{Wu}$ and $\mathrm{Li}$ 2019) and these experiences are usually delivered through stories (Lund, Cohen and Scarles 2018), which communicate values and ideas as people are transported into the imaginary world of the stories empathizing with the characters and adopting the message (Van Laer, De Ruyter, Visconti and Wetzels 2014; Martin 2010). Stories are imperative in providing destination brands with uniqueness, personality and an emotional connection (Bierman 2012; Fog, Budtz and Yakaboylu 2005; Hosany, Prayag, Van Der Veen, 
Huang and Deesilatham 2017). In online spaces, storytelling boosts the persuasive impact of brands which drive consumers into action (Dessart 2018; Pera and Viglia 2016; Van Laer, Feiereisen and Visconti 2019). Storytelling is therefore useful in the context of influencing social media users' perceptions and guiding their co-creative activities.

The concept of co-creation has long been recognised as a significant product development and marketing tool (Lusch and Vargo 2006; Prahalad and Ramaswamy 2004). With the emergence of social media consumers are empowered to co-create brands (Fournier and Avery 2011; Gensler, Völckner, Liu-Thompkins, Wiertz 2013; Singh and Sonnenburg 2012). In contrast to the traditional integrated marketing paradigm, where a high degree of control was present, social media-based conversations are now occurring outside marketers' direct influence (Mangold and Faulds 2009). Indeed, the critique of co-creation in existing literature generally views this reconfigured relationship between producer and consumer in a positive frame as the power relationships within product communications elevates the subjective voice of users.

Nevertheless, brand co-destruction through conversations and shared stories by users in social media remains an under-researched topic (see Hollebeek and Chen 2014; Nam, Baker, Ahmad and Goo 2018; Swaleha, Samy and Jones 2017). No study to date has examined this in the context of social media and destination branding (c.f. Vallaster, von Wallpach and Zenker [2017] on co-destruction of destination brands outside of social media). It is therefore the premise of this paper to explore ways for DMOs to avoid or reduce brand co-destruction and generate brand co-creation.

Brand co-destruction occurs in consumer-to-consumer $(\mathrm{C} 2 \mathrm{C})$ conversations in brand communities where negative comments about a product or service are prevalent (Swaleha et al. 2017). Users are involved in brand co-creation and co-destruction through their conversations and shared stories; jointly creating spaces of contestation and producing storytelling performances which affect the preferred brand narrative. Brand co-destruction can thus be a 'vicious cycle' as shared negativity about a brand generates further negativity (Nam's et al. 2018). Social media therefore may manifest as a 'Pandora's box' as they become vehicles for a virtual anti-brand community through which boycotts are organized and discontent is expressed (Jin 2012). For instance, in September 2018 Nike launched an ad campaign with controversial NFL player Colin Kaepernick, triggering a social media movement advocating a boycott of Nike products which caused a fall in Nike's share prices (Kelner 2018). Marketers, especially DMOs, are prioritizing social media in terms of branding (Hays, Page and Buhalis 2013; Lund et al. 2018; Usakli, Koç and Sönmez 2017), and are reliant on users to spread the 
word and thus co-create the brand with them. The potential of brand co-destruction is therefore a fundamental threat to their branding efforts, which consequently can directly affect brand performance and product viability.

Co-destruction and co-creation have hitherto largely been observed as binary concepts due to the focus on either co-destruction (see Plé and Cáceres 2010; Echeverri and Skålén 2011; Smith 2013) or co-creation (see Gensler et al. 2013; Banks and Deuze 2009). However, this is a false dichotomy as brand co-destruction and co-creation can co-exist as value is multifaceted and encompasses several dimensions (Plé 2016). This paper therefore suggests that users' value creation in social media is a dynamic process generated along a 'brand value continuum', in which user generated content (UGC) is often neither particularly co-destructive nor co-creative but relatively neutral. Hence, often UGC neither co-destroys nor co-creates the brand but instead keeps it rather stable with neither overtly positive or negative things to say about it. Furthermore, brand 'co-destruction' is usually understood as two or more actors integrating their resources in destroying or undermining brand value and it is misleading to label users as co-destroyers if only one partner is misusing resources (Vafeas, Hughes and Hilton 2016). This paper therefore seeks to address this issue and strengthen the focus on the fluidities and multifaceted manifestations of joint brand co-destruction and co-creation. As such, this paper has three objectives. First, to examine how brand co-destruction can be a fluid process of varying degrees and multiplicities in which value is continually diluted, generated or kept unaltered by various actors along a brand value continuum. Second, to identify empirical examples of co-destruction where multiple users jointly co-destroy the destination brand intentionally and unintentionally. Third, to critique how storytelling in social media can counter brand co-destruction directly or indirectly.

Based on a netnography of TripAdvisor and Facebook, combined with a case study of the DMO, VisitDenmark, the destination brand engagement of social media users is empirically examined. Of particular interest are the ways in which stories created by users undermine or reinforce the DMO's preferred brand narratives of Copenhagen, especially its two main attractions, Tivoli Gardens and Christiania. The paper proposes a new understanding of cocreation and co-destruction, transforming the idea of a brand as fluid and multifaceted (Plé 2016) into a comprehensive theoretical framing conceptualized as the brand value continuum. Within this framing, it investigates how DMOs can counter brand co-destruction and strengthen co-creation through storytelling, thus strengthening DMOs' branding strategies and practices. 


\section{Theoretical background}

\section{Developing the brand value continuum: Brand co-creation and co-destruction}

It has long been established that brands are co-created in social media due to the empowerment of users (Fournier and Avery 2011; Gensler et al. 2013; Singh and Sonnenburg 2012). Cocreation involves a joint creation of value as part of a process of resource integration and exchange by marketers and consumers interacting to circulate media content and improve the experience for the user (Prahalad and Ramaswamy 2004; Banks and Deuze 2009). As organic social processes, continually negotiated by multiple stakeholders (Iglesias et al. 2013), brands are increasingly the product of people's conversations in social networks, rather than marketing strategies alone (Fournier and Avery 2011). Social media have facilitated 'open source branding' where brands are embedded in cultural conversations (Ibid). Singh and Sonnenburg (2012) view brands as co-constructed improvised performances that change with each story; the product of improvisational theatre where social media users play different roles. The construction of brands can therefore be interpreted as a collective, active co-creational process involving several brand authors who all contribute their stories (Gensler et al. 2013).

Nevertheless, the concept of value co-destruction has gradually gained more traction in recent years (Echeverri and Skålén 2011; Plé and Cáceres 2010; Vafeas et al. 2016) as researchers further critique the spectrum of behaviours and practices that such co-performance affords. In their pioneering paper, Plé and Cáceres $(2010,431)$ defined value co-destruction of a service/product as "an interaction process between service systems that results in a decline in at least one of the system's wellbeing (which given the nature of the service system can be individual or organizational)". It occurs when a service system accidentally or intentionally misuses resources (its own resources and/or those of another service system) by acting in an inappropriate or unexpected manner (Ibid). In the consumer market, value co-destruction emerges when customers 'misbehave' through, for instance, offline service situations, boycotts or online interactions such as reviews (Järvi et al. 2018), or due to an absence of information or inadequate communication (Vafeas et al. 2016).

Therefore, and at risk of putting it too simply, in the context of social media, users' behavior such as posting negative reviews on a company's Facebook page or on TripAdvisor can harm the company's brand (Järvi et al. 2018, Hollebeek and Chen, 2014; Nam et al. 2018; Swaleha et al. 2017). For example, in their study of user conversation on the Facebook pages of Tesco and Walmart, Swaleha et al. (2017) observe that destruction of value occurs during $\mathrm{C} 2 \mathrm{C}$ conversations online as customers use pages of Tesco and Walmart to provide information 
about better deals at competitors' outlets. Hollebeek and Chen (2014) examine how online brand communities of Apple and Samsung are providing negatively valenced word-of-mouth in their brand engagement. Likewise, Nam et al. $(2018,14)$ demonstrate that value codestruction can be a "vicious cycle" as users" expectations are disconfirmed in real life that in turn causes distrust in previous online reviews. Overall, the extant research on brand codestruction in social media illustrates how users are empowered to become forceful actors in influencing brand narratives, potentially leading to brand co-destruction.

As aforementioned, there remains limited research into co-creation and co-destruction of destination brands in social media, particularly within the service sector. Some critique how DMOs use social media to co-create with users by encouraging interactivity through images and videos (Hays, et al. 2013; Usakli et al. 2017), while Munar (2012) examined the ways in which DMOs integrate social media and its co-creative features into their destination marketing. Others focus on the consumer side, as for instance, Mak's (2017) study of travel blogs that illustrates how social media have empowered users to co-construct destination brand narratives as they can recreate their 'gaze' to an online audience. Pera's (2017) study of online reviews investigates the co-creative behaviors of users through storytelling yet does not examine the impact on destination brands. The only study to thus far examine co-destruction of destination brands explores how the recent refugee crises and terrorist attacks in Germany have codestroyed the previous positive brand of Munich (Vallaster et al. 2017). The co-destruction of destination brands in social media is therefore an entirely novel research topic yet understanding the complexities of such practice holds significant contribution to knowledge and practice. Indeed, as it can potentially have a negative impact on tourist numbers, the lack of prior research is surprising.

This paper builds upon concepts proposed by Vafeas et al. (2016), Plé (2016) and Smith (2013) who focus on value creation in products and services. For instance, Vafeas et al. (2016) examines the accuracy of the term 'value co-destruction' as an all-encompassing term as it implies irreparable loss. As the process of interaction and resource integration may result in value reduction, the term 'value diminution' may be more appropriate, as some of the value promised and expected may still be realized. Therefore, the product may still generate some improvement in the customer's (and provider's) wellbeing (ibid). Likewise, in a conceptual paper, Plé (2016), observes that value destruction and value creation can co-exist as value is multifaceted and encompasses several dimensions such as economic, experiential and relational. One kind of value may therefore be able to compensate for another. For instance, experiential or relational value co-creation may compensate for economic value co-destruction 
for the same actor (Ibid). In other words, a music concert may generate positive experiential and relational value when enjoyed in the company of good friends, but if the drinks were much more expensive than expected, this may cause economic value co-destruction. Co-creation and co-destruction can therefore be parallel results of a value process that involves different actors, and co-destruction might be a step on the path towards co-creation (and vice versa). To that extent, value co-creation and co-destruction can be regarded as two sides of one coin as they can alternate with each other over time or even co-exist for one or more actors of the ecosystem (Ibid). Hence, Plé (2016) suggests the term 'value processes' rather than the employing the binary terms co-creation and co-destruction. As such, the original definition of value codestruction by Plé and Cáceres (2010) has been met with increasing critique.

With regard to brand co-destruction, a similar critique is warranted. Kohli, Suri and Kapoor (2015) observe that once brands are public on social media, users have growing power to renegotiate and fragment the brand narratives in whatever direction they see fit. While a brand initially may embody a manufactured commercialized narrative, people's storytelling may be absorbed into the brand narrative, changing and diluting its original identity and creating a multiplicity of fluid identities as encounters and interactions are shared through narratives (Scarles 2009). However, even though the brand conversation and stories of users may undermine the initial brand identity, they may still create some constructive value as they generate audience reach for the brand in question by sharing and generating further conversations about it.

Through the conceptual framing of a spectrum of co-destruction, this paper extends the critique of the original definition of value co-destruction by Plé and Cáceres (2010) to the context of destination brands, as it examines how destination brand co-destruction is a fluid process where intersecting manifestations of value are continually diluted and generated through multiple practices by various actors. Indeed, by conceptualizing a spectrum of practice of co-destruction, we recognize the fluid and complex behaviors and practices that underpin storytelling and the effect this can have on brand identity. Users' storytelling is part of a dynamic process generated along what we term a 'brand value continuum' (see Figure 1). The content generated by users is sometimes very co-destructive and at other times only slightly so, while at other times the users create varying degrees of co-creative value. However, occasionally the value generated is just neutral, not enforcing nor undermining the preferred brand of the DMO. In these instances of short fluid neutral exchanges, the brand remains relatively stable, not particularly affected by user generated content UGC. 


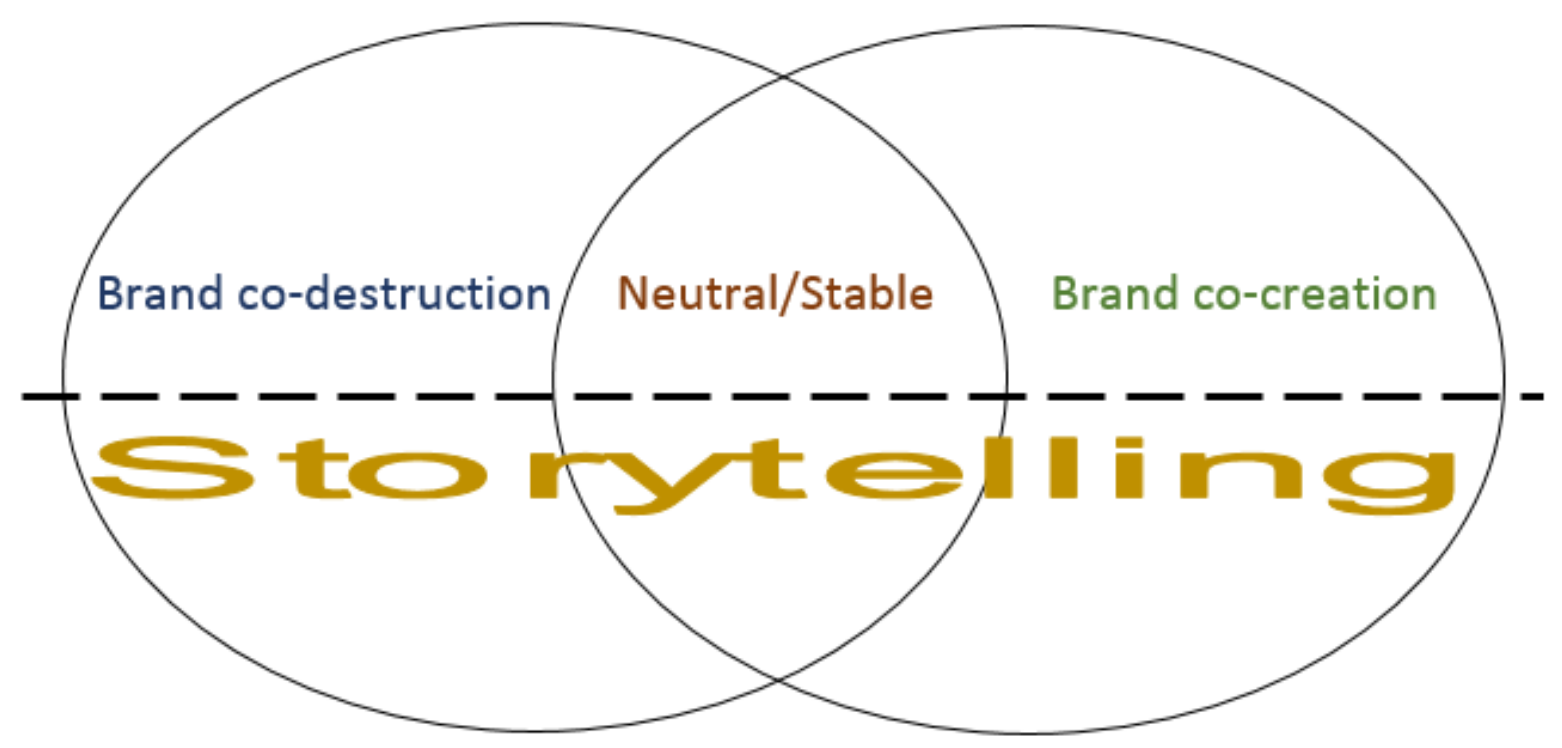

Figure 1. The brand value continuum.

It is also relevant to question the 'co' in co-destruction as this implies that more than one actor is involved in destroying. Co-destruction denotes the joint destruction, or impoverishment of value by businesses and customers (Echeverri and Skålén 2011). As Plé (2016) observes, co-creation increasingly focuses on ecosystem dynamics, which are cocreation contexts that involve multiple stakeholders. It is therefore difficult to continue to adhere to the original definition by Plé et al. (2010) of co-destruction as a one-sided issue causing decline in only one of the service system's organizational or individual aspects. For it to be 'co-destruction' two or more actors have to integrate their resources in destroying the brand value. Furthermore, the reality is that creation of value in social media often involves producers, multiple consumers as well as the social media platform and its algorithms so this makes the situation more complex. Sometimes users do not purposively harm the brand, but it is choreographed by the social media platform's algorithms. As Vafeas et al. (2017) argue, the term 'value diminution' alleviates difficulties with the use of the prefix 'co', as the latter implies 'joint' which is a misleading label if only one partner is misusing online resources. To add to the complexity, co-destruction is a multi-layered phenomenon where, for instance, DMOs and service providers sometimes misuse offline resources and users respond online with their valid concerns, which consequently triggers an online/offline response from the agents involved as well as other interested parties. The co-destruction thus takes place through a series of offline/online interplays throughout the evolution of the relationship between active agents. 
While Vafeas et al. (2017) researched the inter-firm relationships in the creative industries within the context of Service-dominant logic (see Prahalad and Ramaswamy 2004), this research moves into unexplored territory, by examining the co-destruction by an amalgam of actors jointly undermining the preferred version of a destination brand, intentionally or unintentionally.

\section{Employing storytelling to counteract brand co-destruction}

This paper argues that marketers can utilize storytelling to counteract brand co-destruction in social media. Singh and Sonnenburg $(2012,192)$ state that storytelling is "a continuous ongoing and improvisational process made up of interlinked content". This statement captures the fluidity of storytelling as practice and highlights it as a dynamic and evolutionary process as people negotiate their identities. Storytelling is a therefore a collective co-creative process, a sharing activity, which enables social interactions as it generates an emotional shared experience that becomes central to a social media community's identity (Pera 2017).

It is widely accepted among scholars that storytelling is imperative in branding a product (Fog et al. 2005; Lund et al. 2018; Woodside 2010). Essentially, storytelling is at the heart of how brands are shaped; without a special story, there is nothing distinctive about them (Ibid). It provides brands with a personality as they possess familiar human traits such as persistence, courage and imagination (Herskovitz and Chrystal, 2010). Stories come with many touch points to the lives of listeners, facilitating an emotional connection with the brand (Fog et al. 2005; Woodside 2010). Brands can thus differentiate themselves through authentic stories with interesting characters rooted in the reality of the product (Gunelius 2013).

In the digital era, there is a great demand for narrative content (Van Laer et al. 2019). The more memorable the stories are on social media, the more likely they are to be repeated (Mangold and Faulds, 2009). Powerful stories can manipulate people into liking a brand (Tussyadiah and Fesenmaier 2008) as they connect with audiences and impose their values and way of thinking on them (Simmons 2006). Research shows that stories with authentic experiential cues and positive emotions enhances individuals' memory of the story and can positively affect their intentions to visit the destination (Kim and Youn 2017). As narrative transportation theory proposes, when the users lose themselves in a story, their attitudes and aims change to reflect that story, which explains the persuasive effect of stories on users (Van Laer et al. 2014). The users empathize with the story characters and the plot of the story activates their imagination which suspends reality during the reception of the story (Ibid). On 
social media, commercial professional storytellers can appeal to consumers' positive emotions and thus lower resistance to commercial content (van Laer et al. 2019).

However, storytelling also enables social media users in peer-to-peer communities to have rational, emotional, and relationship experiences which moves them into action (Pera and Viglia 2016). Tourists become attached to the destination and identify with its identity through emotions of love and pleasure that are central to meaningful tourism experiences (Hosany et al. 2017). Their shared stories incorporated into online reviews become a powerful value generator as narratives about travellers' behaviours instruct the online community members on how to 'behave' appropriately (Pera 2017). Hence, stories can thus act as an important channel for mediating and transmitting important values, ideas and characteristics of a social group to its members (Martin 2010). Story receivers are emotionally transported into the storyteller's world through empathy and imagery, interiorizing the stories through narrative transportation and making a connection with the protagonist (Pera and Viglia 2016). Hence, storytellers on social media influence each other's attitudes and beliefs. As users share their stories and reviews communicating their perceptions of a destination, DMOs can track these stories to understand tourists' feelings about the experiences they offer (Rahmani, Gnoth and Mather 2017).

Storytelling in social media is an effective way of counteracting value co-destruction in social media as engaging stories can set the agenda for user conversations and influence values and perceptions, as well as expressing the unique attributes of the brand. Brand managers can play a leading role in the co-creation process as they can choose topics that communicate the desired messages, and engaging stories can induce users on social media to co-create and proliferate those messages (Gensler et al. 2013). If a story has sufficient appeal, it can go viral and potentially be shared around the globe. Indeed, DMOs are evermore prioritizing social media in terms of branding (Hays et al. 2013; Usakli et al. 2017) and are reliant on users to spread the word and thus co-create the brand with them (Lund et al. 2018). As Velji (2017) suggests, DMOs need to capitalize on trending topics in social media to promote their destination. However, DMOs should also integrate stories of social media users into their branding efforts as these stories are emotionally persuasive.

Utilised effectively, social media co-creation is a cost-effective method for branding a destination and storytelling can be a conduit for engaging with users and stimulating constructive processes of value generation that are disposed towards the co-creative section of the brand value continuum. However, it is worth noting that storytelling is just one of many instruments in the DMOs' toolkit to counter brand co-destruction. Other ways involve listening 
to the consumers' justified grievances and implementing service recovery strategies (Miller, Craighead and Karwan 2000) to improve the value proposition and service quality (Parasuraman, Zeithaml and Berry 1985). These more practical approaches are beyond the focus of this paper which centers solely on the brand narratives in online social media spaces. DMOs need a stronger understanding of the multi-faceted brand value processes and the potential of storytelling in countering brand co-destruction and generating co-creation. Having established the conceptual framing for the paper, attention now turns to the empirical findings and resulting conceptual contributions to be made.

\section{Methods}

The research upon which this paper is based employed two qualitative methods of data collection to ensure both perspectives of producer and consumer were addressed. The qualitative approach consists of a set of interpretive practices that make the world visible (Denzin and Lincoln 2011). The case of VisitDenmark provides the context and the producer brand-led perspective while the consumer perspective is addressed through netnography, which centers on social media users on the platforms TripAdvisor and Facebook. The research is situated within the constructivist paradigm (Lincoln and Guba 2013) as social media branding demonstrates how meaning and understandings are constructed in the process of interpretation and dialectic negotiations (Constantino 2008).

The case study approach is adopted to understand the social media branding and storytelling practices and strategies of VisitDenmark. Case studies are especially applicable in exploratory research where a new phenomenon is studied (Veal 2006), such as that of social media brand co-destruction of destination brands. Case studies are used to understand a reallife phenomenon in depth (Yin 2013). They provide an intensive analysis of a particular unit (Flyvbjerg 2011) within a bounded system (by time and place) and they explore multiple sources of information rich in context through detailed, in-depth data collection (Cresswell 1998). Case studies provide a more detailed picture of specific practice within the broader context (Garrod and Fyall 2011). VisitDenmark is an independent non-profit organization appointed by the Danish Government to market Denmark internationally to tourists and business travelers (VisitDenmark 2015a). This study of VisitDenmark is an instrumental case study (Garrod and Fyall 2011), as it provides an insightful case to learn wider lessons about how storytelling can counter co-destruction. As VisitDenmark relies heavily on social media 
to brand the destination (VisitDenmark 2014), one case study, in combination with a netnography, was deemed sufficient for the present enquiry into a new phenomenon.

The areas of interest in the case study were VisitDenmark's branding and social media strategies and practices in relation to storytelling and co-creation/co-destruction. A secondary analysis was conducted on VisitDenmark's reports, presentations and website from 2015 2017 (approximately 300 pages) to provide further insights into its brand and social media strategy. There was a specific focus on the brand of Copenhagen, as users on TripAdvisor and Facebook mostly write about Copenhagen, and VisitDenmark has a clear brand identity for the city (VisitDenmark 2015b). Users from the US and UK were targeted, as VisitDenmark has a specific social media brand strategy for these source markets and users from these markets have been especially active on TripAdvisor and Facebook. The posts and reviews targeted were thus all in English.

As part of the case study, the lead author conducted semi-structured interviews each lasting approximately 1.5 hours in-person and by Skype with four senior social media marketing and brand managers within the global VisitDenmark team. The interviewees were the ones in charge of social media branding at VisitDenmark and had detailed knowledge of the depth and breadth of the issues being addressed. Four interviews were therefore sufficient (Saunders 2012). As the objective of the interviews were to have employees explain, clarify and elaborate on existing strategies and practices, semi-structured interviews were deemed most appropriate. The themes covered in the interviews mainly revolved around co-creation and co-destruction, storytelling and branding through social media (Fournier and Avery 2011; Iglesias et al. 2013; Plé and Cáceres 2010). The interviews and secondary data were analyzed using a thematic analysis which captured and interpreted important concepts (Ayres 2008). Categories and themes were developed based on the themes found in the data as well as the themes of the research questions which centered on co-creation, branding and storytelling, with the analysis assisted by NVivo.

A netnography was conducted by the lead author on selected posts from TripAdvisor and Facebook from July 2015 to August 2018 as part of the case study. TripAdvisor was chosen for data collection as it is the largest platform for personal travel reviews and it holds 600 million reviews and has 455 million unique monthly users (TripAdvisor, 2018a), while Facebook was chosen as it is VisitDenmark's main online platform for branding and communicating with consumers. The lead author was granted access to VisitDenmark's Facebook account as an 'Insights Analyst', which enabled him to also view user comments hidden from public as they were seen as offensive. VisitDenmark also use other platforms such 
as Instagram and Twitter but there is significantly less content produced for them and therefore they were not selected for data collection. Facebook is the world's largest social media platform with 2.4 billion users (Statista, 2019) and is used for staying connected with friends and family while sharing and consuming content. Thus, it is often used for communicating tourism experiences (Gössling and Stavrinidi 2015). Facebook thus provides an effective data source for examining the interaction between users and VisitDenmark. The netnography on Facebook and TripAdvisor provides an opportunity to understand peoples' everyday social behavior as social media increasingly become part of human nature (Kozinets 2015). The netnography had two objectives. First, to understand VisitDenmark's social media strategy and practices by observing their social media activities and how followers interacted with these activities. In that sense the netnography contributes to the case study. Second, it examines how Facebook and TripAdvisor users jointly create content that co-create and co-destroy the preferred brand narrative of VisitDenmark.

The sample selection criteria are somewhat different for the two social media platforms. On Facebook, posts focusing on Copenhagen for the US and UK users with more than 5 comments were chosen as the content of the comments illustrate how users undermine or reinforce the preferred narrative of the post. On TripAdvisor, reviews from US and UK users with extensive accounts, i.e. two lines or more, of experiences with specific attractions in Copenhagen (specifically Christiania and Tivoli Gardens were selected as they show how storytelling influences brand value of a particular attraction as part of the Copenhagen's brand). The sample was therefore non-probability purposive, as it was chosen for studying interactions between VisitDenmark and their social media followers (O'Reilly 2009). For the purpose of this article we chose to focus on those whose posts had gained some traction and/or were substantive enough to illustrate the power of storytelling. Hence, both rare and regular posters were included in the sample. The Facebook posts and TripAdvisor reviews were anonymized with the users given pseudonyms (e.g. Follower 1 for Facebook/Reviewer 1 for TripAdvisor).

VisitDenmark's preferred brand narrative for Copenhagen is a historical, cultural city with award-winning architecture, townhouse boutiques, gourmet offerings, great art and with open spaces for relaxation and contemplation (Brand Denmark 2015b). The brand promise is "Come and be part of it" which entails that people play, learn, explore and spend time together (Brand Denmark 2015a). Christiania and Tivoli Gardens are two of the main attractions in Copenhagen and are therefore reviewed daily on TripAdvisor. They are also the subject of several VisitDenmark posts. They were selected for analysis as users create multiple narratives about them. Christiania is a collection of old army barracks which were vacated by the military 
in 1971 and subsequently became known as the Freetown of Copenhagen; a self-governing society based on sustainability, alternative hippie lifestyles and experiments. Tivoli Gardens is an amusement park at the center of Copenhagen, founded in 1843, which serves as a popular place for recreation with its rides, concerts, restaurants and scenic spots.

A total of 80 Facebook posts and 100 TripAdvisor reviews represents all posts and reviews from US and UK users that fits within the above mentioned criteria during the timeframe of this study from July 2015 to August 2018. They were subjected to discourse analysis, which is a method to study language use and its role in social life and in constructing the world (Potter 2008). The method draws its ideas from social constructivist epistemology that views language as constructive and constructed (Gill 2000; Phillips and Hardy 2002). As it examines how processes of social construction lead to a social reality that advantages some participants at the expense of others (Phillips and Hardy 2002), discourse analysis is an appropriate way to assess the ways in which users co-create and co-destroy brand value. Furthermore, as discourse analysis mainly focuses on any naturally occurring text, such as the ones found on social media, it is suitable for netnographies as participant observation is ideal for capturing "naturally occurring" discourse (Guest, Namey and Mitchel 2013). The categories used for coding were determined by the components of the preferred brand narrative of VisitDenmark, as, for instance, 'culinary excellence', 'historical and cultural activities' and 'design' (Brand Denmark 2015b). Hence, the texts were examined for discourses and constructs which produce aspects of reality as presented by VisitDenmark and users (Cheek 2008). The interview material and secondary data from the case study is combined with the netnographic material in the following findings sections, which examine how brand codestruction and co-creation exist along a brand value continuum and how storytelling counters brand co-destruction.

\section{Findings}

\section{The brand value continuum}

This paper views the destination brand co-destruction as a fluid process without clear dividing points and with intersecting multiple manifestations of brand value along a brand value continuum (see Figure 1). This can be identified in three ways by examining TripAdvisor reviews and Facebook posts: First, some stories might be very destructive towards the brand while others are less destructive, suggesting there are varying degrees of destructiveness. Second, destination brand co-destruction can be seen as a fluid dynamic process where value 
is continually diluted and generated by various actors. Third, there are also user stories that are relatively neutral in their critique, which do not have a destructive nor creative impact on the brand value. In the following, the stories of DMOs and social media users are examined and interpreted. Due to word count limits, only short extracts and vignettes from users' more extensive stories are presented.

Some user stories are very destructive towards the brand while others are less so, indicating varying degrees of destruction. An observable example can be found in TripAdvisor reviews of Christiania. VisitDenmark presents Christiania as a vibrant alternative hub and as "The hippie freetown that never grows old" and continues "Christiania is a real experience; a hotch-potch of warehouses, huts and houses, colourful murals and outdoor sculptures" (VisitDenmark, 2016a). However, the head of branding for VisitDenmark also observes that the DMO does not try to hide that Christiania has problems, but it is "very interesting to experience Christiania as part of understanding what is Denmark". The photos of Christiana from VisitDenmark's official website illustrates how Christiana is portrayed as a green, authentic, friendly and idyllic attraction (see Figure 2). The users want "pretty pictures ... a beautiful view" as the DMO's head of digital media states.

However, on TripAdvisor a different narrative about Christiania is presented with very mixed reviews, in which $42 \%$ of reviews are ranging from 'Average', 'Poor' and 'Terrible' (TripAdvisor, 2018b). Hence, when readers scroll down TripAdvisor's page on Christiania they find a list of reviews where there are varying degrees of co-destructive stories published. For instance, reviews call Christiania a "vile place" (27/8/2018), "a bitter disappointment" (July 31, 2018), and an "awful place" as part of their larger stories (17/10/2018). However, others are less negative, stating, for instance, "Intimidating spot but probably unique" (26/10/2018), or "Dirty and interesting" (19/7/2018), and "the street art and jewellery is pretty but that's all" as part of their account. (5/7/2018). Hence, some reviews are evidently undermining the preferred brand narrative of VisitDenmark, while others are less destructive and partisan. They acknowledge some positive aspects as well. Brand co-destruction therefore comes in various forms and intensity, which strengthens Vafeas et al.'s (2016) argument that the term 'value diminution' may be more appropriate than 'value co-destruction' as some of degree of value may still be achieved. 


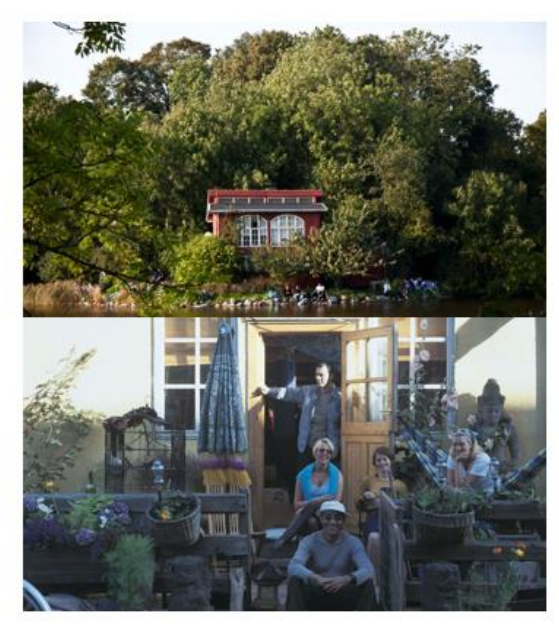

Figure 2. Christiania. Adapted from VisitDenmark's (2018a, 2018b) website.

The list of reviews on TripAdvisor demonstrate how destination brand co-destruction can be seen as a fluid dynamic process where value is continually diluted and generated by various actors along a brand value continuum. When people scroll down the TripAdvisor page, they will see reviews that work to destroy or enforce the brand value. With each new review being written on TripAdvisor, the narrative changes. For instance, in reviews of Tivoli Gardens, Reviewer 1 sees the attraction as "quirky, delicious, surprising, vintage, FANTASTIC!" (10/10/2018). This is in line with how Tivoli is presented by VisitDenmark (2016b) as it is described as a magical fairy-tale land, an exotic cultural wonderland, a historical gem connected with the author Hans Christian Andersen. However, the next TripAdvisor review states that it is "overall fun but not worth the cost" (10/10/2018). Similarly, in the comment sections of VisitDenmark Facebook posts, one comment might be supportive of the brand narrative while the next is countering the narrative (see Figure 6). The fluid brand changes with each new comment, post and share, and moves back and forth, appearing at various spots along the brand value continuum. It shows how value co-destruction co-exists in relation to cocreation and is generated by a plethora of voices (Plé 2016), and it enforces Iglesias et al.'s (2013) argument that brands are organic social processes continually negotiated by multiple stakeholders. The brand value continuum enables a visualization of these co-constructed interlinked performances of the storytelling which generates brand value.

As there are varying degrees of co-destructiveness and co-creativeness, there are also user stories that are relatively neutral in their critique. As Plé (2016) suggests, value destruction and value creation can co-exist. However, towards the middle of the brand value continuum (see Figure 1) co-creative and co-destructive stories do not just co-exist, they fuse together into brand value that maintains the brand in a stable position, being neither particularly harmful nor 
positive about the brand. For instance, in the reviews of Christiania, Reviewer 3 notes "There are nice wall paintings, but you don't have to travel to Christiania just for these" (3/7/2018), while Reviewer 4 states "Interesting concept of an anarchical type society set in the capital. Glad I got to see it but if you've got limited time I wouldn't be too pushed to prioritize it over of other attractions" (37/2018). These reviews are rather impartial, neither discouraging nor encouraging a visit to Christiania. While Gensler et al. (2013) argue that the construction of brands is a collective, active co-creational process involving several brand authors who all contribute their stories, it can also be said that often these stories are not particularly co-creative nor destructive. In their neutrality, they add to the brand's stability.

\section{The (un)intentional joint co-destruction of destination brands}

Having looked at the fluid process of value creation along the brand value continuum, attention now turns to the intentional and unintentional joint co-destruction of destination brands. As Vafeas et al. (2017) argue, for it to be 'co-destruction' two or more actors have to integrate their resources in destroying value. The findings show two main types of genuine codestruction. First, there is co-destruction which is not done purposively, but rather where codestructive stories are bundled together and jointly undermine brand narratives. Second, there are instances where users jointly co-destroy the brand through their comments and conversational trails feeding off each other fueled by the empowerment facilitated by social media (Fournier and Avery 2011).

Social media sites such as TripAdvisor and Facebook enable incidental unintentional co-destruction via their algorithms. For instance, TripAdvisor order their reviews according to the date and time they were created. Figure 3 shows three reviews listed above one another and written in succession of each other; all three have a negative view of Christiania. They focus on how Christiania is perceived as dirty and unsafe with drugs sold openly. When readers scroll through the reviews on TripAdvisor and several negative reviews are bundled together it creates an incidental artificial choreographing of joint co-destruction which elevates a sense of dissatisfaction and a negative brand narrative. Similarly, on Facebook, users who write comments to a post can be associated with previous comments of a similar persuasion, creating an overall negative (or positive) narrative of the place. 


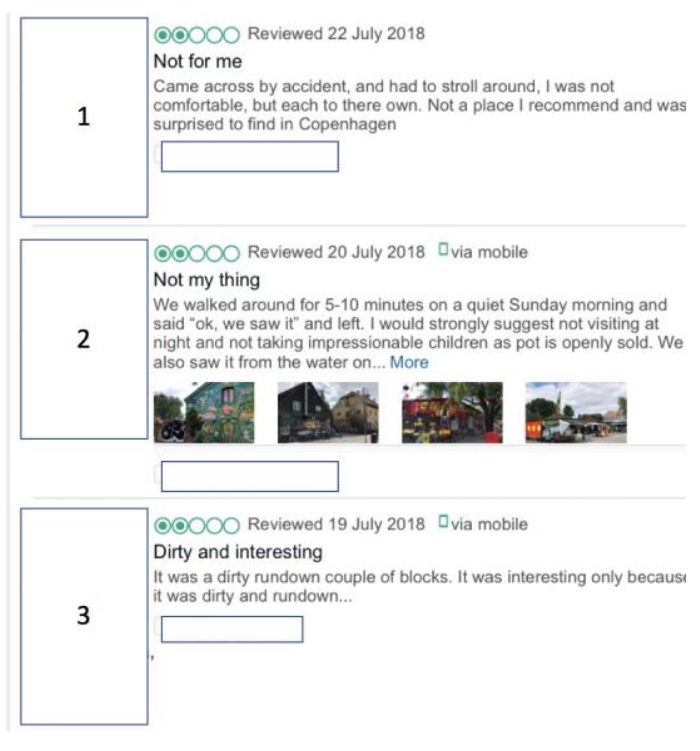

Figure 3 Reviewers not purposively co-destroying a brand (TripAdvisor 19 - 22 July 2018).

However, the bundling of positive comments may not be entirely incidental as VisitDenmark has the ability to hide comments they find offensive, as the head of digital media at VisitDenmark points out (see Figure 4 for example). These comments are then only visible to VisitDenmark. Hence, the DMO has the power to interfere in the presentation of social media and design a more favorable collective brand narrative. The findings thus provide nuance to Swaleha et al.'s (2017) view that destruction (or creation) of value occurs during C2C conversations, as other stakeholders (the social media platforms, the marketers) are involved in the process as well. The brand value is to some degree determined by algorithms and marketer's interference. While there is a degree of user empowerment to co-create brands (Gensler et al. 2013), the content of users is being renegotiated and organised by other commercial and governmental stakeholders to present a narrative that is either more preferable or easily consumable.

Intentional co-destruction is where social media users work together to undermine the preferred brand narrative. As Nam et al. (2018) argue, brand co-destruction can be a 'vicious cycle' as shared negativity about a brand generates further negativity. A suitable example of this is a post (Figure 4) in which VisitDenmark presents an image of warm and fun Copenhagen, which fits their brand promise "Come and be part of it", entailing that people play, explore and spend time together (Brand Denmark 2015a). However, multiple users purposively jointly undermine the positive message and try to direct attention to a different cause. Many of the comments focus on the cause of the whale killing in the Faroe Islands, which is an issue that arises every year when the Faroe people kill whales off the coast. It brings bad publicity to 
Denmark and users target the Danish ministry as well as VisitDenmark as an outlet for their anger, according to the DMO's head of Digital Media. Users are interacting with each other's comments and cooperating in protesting against the whale killings. For instance, Follower 2 writes "Good one" as an encouragement and approval to Follower 1 who writes "I'd rather go visit hell". Furthermore, Follower 4 states “Whale killers!!!!!!!” likely in response to the previous statements and images. Hence, the users spur each other on, feeding off each other's images and comments. The post is therefore an example of genuine destination brand co-destruction as users purposively jointly co-destroy the message and thus undermine the preferred destination brand. It illustrates how users' behavior such as posting negative reviews on a company's Facebook page or on TripAdvisor can harm the company's brand (Jarvi et al. 2018) and manifests Fournier's and Avery's (2011) statement that social media have facilitated 'open source branding' where brands are embedded in cultural conversations.

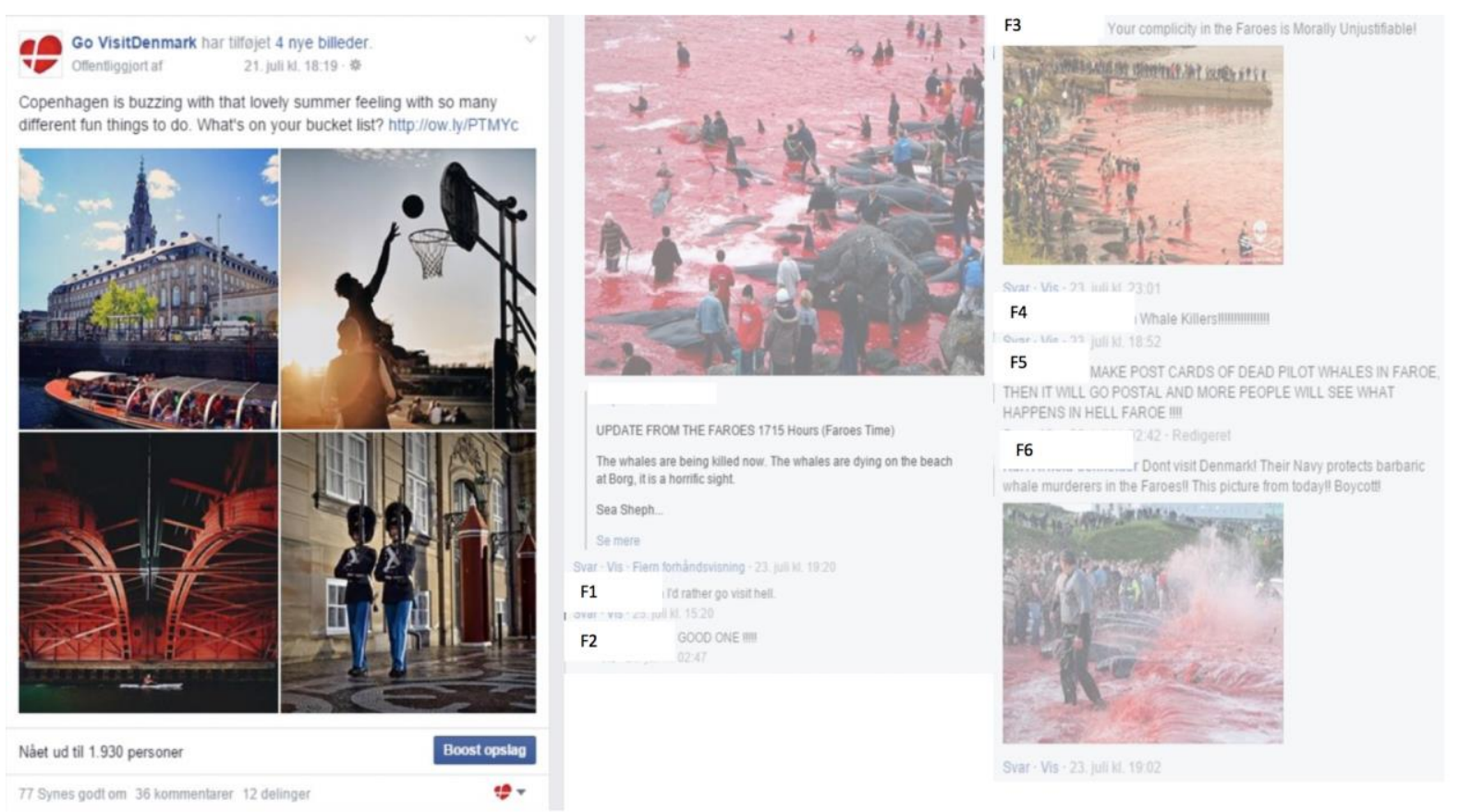

Figure 4 VisitDenmark post co-destroyed by various users (adapted from VisitDenmark 2016).

All the posts were hidden by VisitDenmark and therefore not visible for users.

However, VisitDenmark can also destroy value. As mentioned VisitDenmark can hide comments. According to the US online manager of VisitDenmark, VisitDenmark monitors the comment sections: "we monitor as best we can with the limited resources that we have, so sort of make sure that it is... not too offensive". As the head of digital media states, "we don't hide it if someone had had a negative experience; they can share that if they want to but we hide it if someone is posting bloody pictures of whaling". According to their guidelines, they 
can hide comments if users are posting offensive and inappropriate, obscene comments or graphical images. The comments about whales in the Facebook post were therefore all hidden from the other Facebook users as they were seen as offensive by VisitDenmark. Hence, VisitDenmark destroy content that other users may perceive as value. It underscores the assertion by Plé (2016) that value co-creation and co-destruction can be regarded as two sides of the same coin as they co-exist. In this case, value creation for the whale slaughter opponents is seen as value destruction by VisitDenmark. It illustrates how brand value is a multi-sided phenomenon, in which the perspective of the actors involved determine what is regarded as value. It relates back to the brand value continuum (see Figure 1), as value is not only dynamic and comes in varying degrees but the interpretation of value on the continuum depends on the subjective opinion of multiple stakeholders (users, marketers, social media platforms), each having a different perception of what is of value. Hence, what is destructive for one user may be creative for another within the spectrum of the brand value continuum. As Plé (2016) asserts, co-creation should focus on complex ecosystem dynamics. This paper provides the empirical data to underscore this assertion, while also expanding it into the sphere of social media branding where the dynamics and politics of discursive counterpoints are prevalent.

The destruction of content in social media feeds into a larger discussion of protecting freedom of speech in online spaces dictated by algorithms and commercial interests. Complying to its speech policy, Facebook moderates and takes down content it sees as harmful (Editorial board 2019), while its algorithms increase polarization by showing users what they like to see in 'echo-chambers' (Hendricks and Hansen 2014). Commercial actors hide post comments that do not fit their agenda, while sharing and promoting other comments that do. Although the control of brand identity can be regarded as disseminating the most positive version of reality in terms of a product, it may also be a question of stifling freedom of speech as commercial actors cover up issues they do not want to discuss or acknowledge.

Brand co-destruction can, however, also have positive implications. Not only for the user who undermines the brand, but also for the marketer. As the online manager of VisitDenmark conveys "actually every time people write a comment, even if its negative, it will help our reach even still". Hence, negative comments do not necessarily have negative consequences, as conversations about the brand contributes to a higher visibility and thus higher brand recognition. The viewpoint challenges the co-destruction concept in terms of branding (see Nam et al. 2018; Swaleha et al. 2017), as even brand co-destruction can be viewed as value co-creation with regard to reach. One kind of value may therefore be able to compensate for another one (Plé 2016). However, the findings strengthen the argument of 
Bierman (2010) that without a special story, there is nothing distinctive about a brand. In this case, it is a negative story which provides higher visibility.

\section{Countering brand co-destruction through storytelling}

This section builds upon the conceptual framing of the brand value continuum by addressing the importance of storytelling in countering brand co-destruction. It addresses how users are enticed to contribute stories that co-create brand value and thus indirectly counter brand codestruction. It also examines how positive storytelling can directly counter brand codestruction.

Storytelling is a vehicle for creating positive brand narratives for VisitDenmark. As the head of branding states: "we don't have that big budgets so we need to reinforce and retell the same story again and again" and she continues "you have to focus on the good storytelling that emphasize our brand promise and the themes". The head of digital media agrees "as long as it is a positive experience, it's the right story". Hence, on Facebook, VisitDenmark's daily postings reinforce the positive stories of Copenhagen and Denmark framed within the preferred brand narrative, which the users are encouraged to contribute to. An insightful illustration of how users are enticed to support the preferred narrative of VisitDenmark is a post with images by the DMO that has a story about Tivoli Gardens (see Figure 5). VisitDenmark informs users that the garden is now celebrating its 175 th birthday and asks people to share their favorite Tivoli moment. It causes 161 users to share their personal memories in the comment section and Figure 5 shows a small portion of these. For instance, follower 1, 2 and 3 speak to each other about packing and going to Denmark, while Follower 4 reminisces about their wedding anniversary which they spent in Tivoli Garden. Followers 5 and 6 share stories about their time there: how it rained and how they lost a balloon.

The example illustrates how DMOs with the right branding 'raw material' can actively encourage users to contribute stories about the brand (Gensler et al. 2013). VisitDenmark comments on almost every user comment and interacts and listens and thus encourages further user comments. As their online manager for the US observes: "if you can sort of write something that people find interesting and then sort of get them to sort of chime in with their own opinions, own words, it obviously helps", while the head of branding notes "authenticity and emotional communication is essential to get people's attention". Hence, they capture the attention of consumers and create engagement through dialogue (Hanna et al. 2011). The 
example also illustrates how stories that come with many touch points to the lives of listeners can facilitate an emotional connection (Woodside 2010).

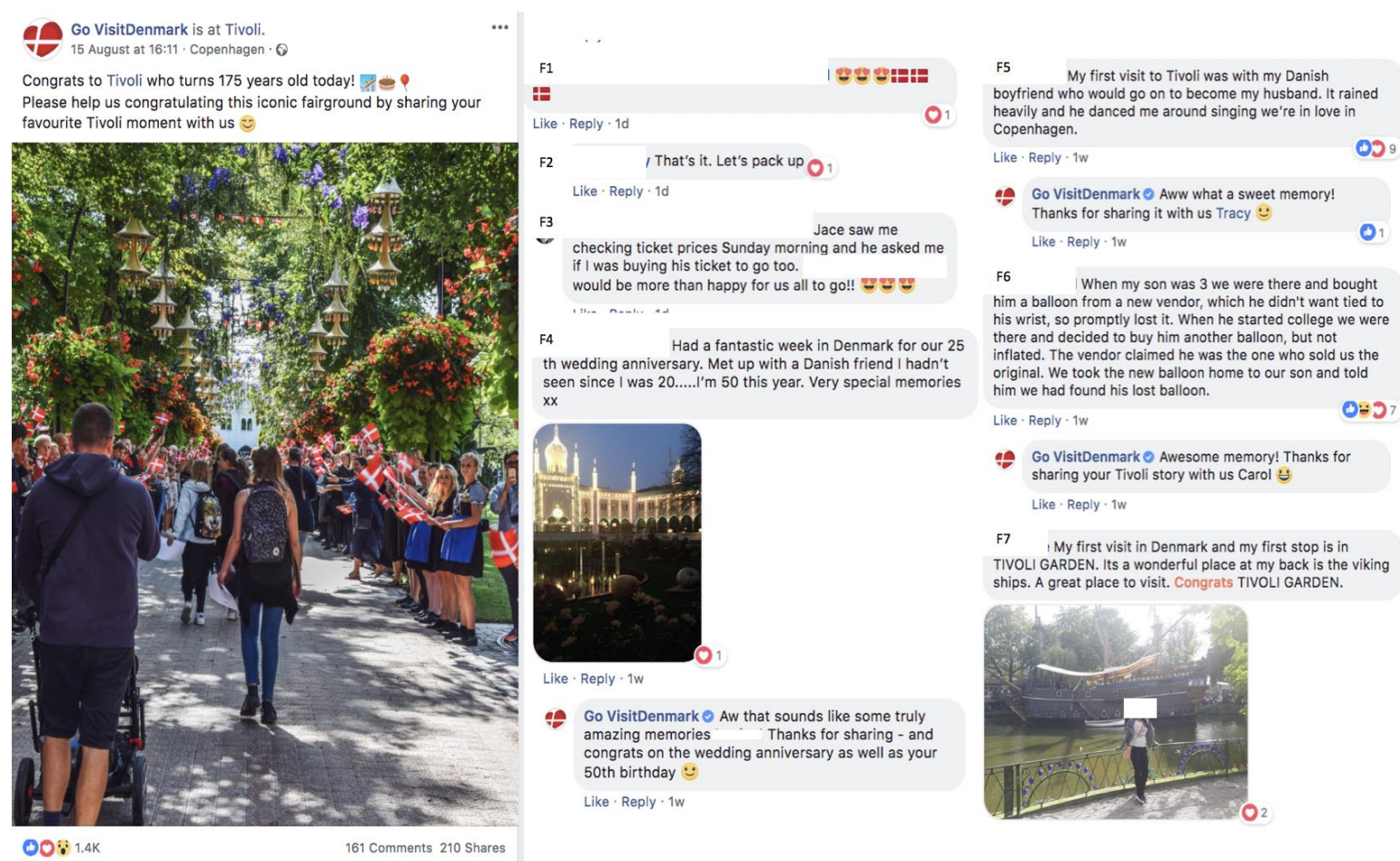

Figure 5 VisitDenmark publishes a post celebrating Tivoli Gardens 175-year birthday, adapted from Go VisitDenmark (16 August 2018).

The example of Tivoli Gardens also demonstrates how a positive narrative can divert attention away from destructive stories. It confirms the findings of Van Laer et al. (2019) that commercial professional storytellers in social media spaces can appeal to consumers' positive emotions and thus lower resistance to commercial content. As the head of branding suggests: "if people have a wrong perception about your place, you can try to tell more about something else, about something positive" and she continues, referring to the whale killings in the Faroe Islands: "you cannot try to say to people, you're wrong, because it's their perception. So it is better for us just to tell the positive stories in the same time". Hence, storytelling can set the agenda and influence users to co-create a positive message through stories and images, which can lead the attention away from brand co-destruction. This relates back to the brand value continuum where storytelling plays a fundament role (see Figure 1). Storytelling is a collective co-creative process, a sharing activity, which enables social interactions, generating an emotional shared experience that becomes central to a social media community's identity (Pera 2017). Hence, the strengthening of the brand's co-creative social aspects distracts from the codestructive aspects as users join together as a community. These findings support the argument 
by Tussyadiah and Fesenmaier (2008) that the narrative power of stories can manipulate people into liking a brand; that stories can have a persuasive effect on users (Van Laer et al. 2014). Even in the sense that they divert attention away from negative co-destructive stories.

Positive storytelling can directly counter brand co-destruction as well. TripAdvisor reviews of Christiania provide ample examples of reviewers who explicitly refute the negative stories written in other reviews by presenting a more positive narrative of the place. For instance, one reviewer, giving 5 stars, writes: "Cool spot" and continues "The graffiti is enough to keep you walking around in awe. Very cool counter-culture vibe. Don't be afraid of things you here [sic] on reviews, etc. everyone is very chill” (11/02/2018), while another reviewer, giving 4 stars, states: "Skeptical after reading reviews, but this attraction was as much fun as any others I've experienced in Copenhagen" (16/06/2017). Finally, a reviewer, giving 5 stars, proclaims "Hippy Happiness.." in the heading and goes on to say "The negative reviews are clearly from people who had no idea what to expect. It is not intimidating at all, and whilst lots of people are smoking dope, there are no hard drugs and it's all very calm and peaceful" (10/12/2019). The reviews demonstrate how brands are generated through co-constructed performances of storytelling that change with each new user review; they are the product of improvisational theatre where social media users play different roles (Singh and Sonnenburg, 2012). Users act with agency and take upon themselves to play opposing roles in the public spectacle on social media. They undermine and contradict other users' viewpoints and tell their personal stories with the deliberate objective of creating a more positive reputation of a place. Hence, they actively counter brand co-destruction.

Another useful example of how positive storytelling can directly counter brand codestruction is provided by VisitDenmark's Facebook post (12/10/2015) that congratulates the US ambassador to Denmark on getting married in Copenhagen (Figure 6). In Denmark marriages between same sex partners are legal. The post was for the US market and targeting the LGBT community, which are one of VisitDenmark's target groups. 


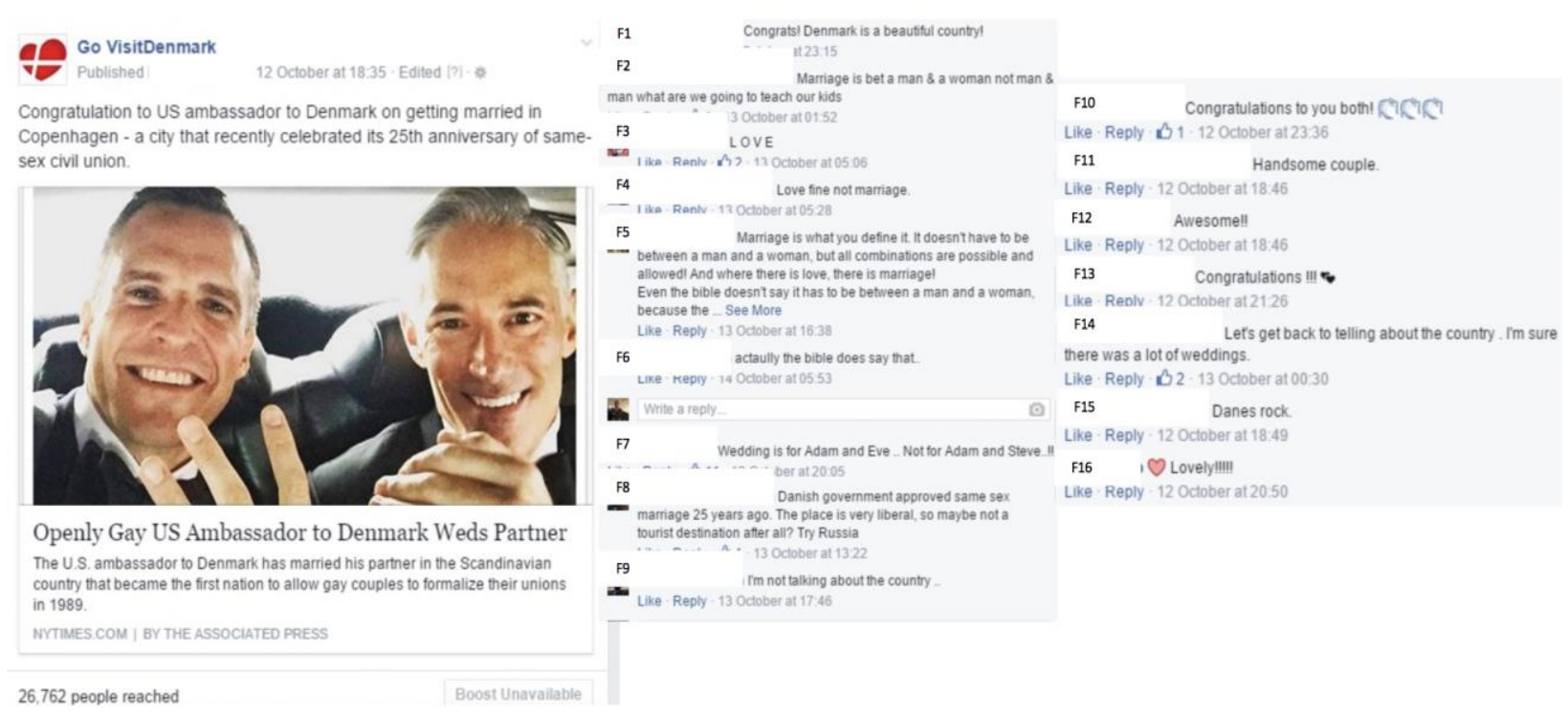

Figure 6 VisitDenmark post celebrating US Ambassador wedding (adapted from Go VisitDenmark 12 October 2015).

A large proportion of fans are aligned with the brand message and are supportive of the marriage such as Follower 1 who writes "Congrats! Denmark is a beautiful country!" and others who say "congrats", "lovely" and "awesome". However, there are also spaces of contestation and opposition; followers who are undermining the preferred narrative. For instance, Follower 2 argues that marriage is between a man and a woman only. Follower 5 opposes Follower 2's view and argues that where there is love there is marriage and she argues that the bible does not specifically say it has to be between a man and a woman. Follower 7 equally argues that marriage is for Adam and Eve, not Adam and Steve. Perhaps the marriage message does not suit segments of VisitDenmark's Facebook followers in the US, who may have various religious or political reasons for arguing against such union. The post promotes Denmark as a liberal and open country, but it quickly becomes a political discussion; the message is fragmented and renegotiated and diverted away from the happy occasion. VisitDenmark did not hide these discussions. As the head of branding states, "I do not think it is possible to influence what they (the users) say about Denmark, I think it is too broad a subject, it is not like it is washing powder or something".

The example shows how positive storytelling can counter brand co-destruction. Stories can act as an important channel for mediating and transmitting important values, ideas and characteristics of a social group to its members (Martin 2010) and they can have a persuasive effect on users (Van Laer et al. 2014). The users positive to the message take upon themselves to discuss and argue with those who oppose the message. Hence, it demonstrates how stories 
in peer-to-peer communities can create emotional and relationship experiences which move users into action (Pera and Viglia 2016). It fits with VisitDenmark's strategy of creating ambassadors through social media. The head of digital media states that ambassadors "follow us on social media and we can have that dialogue with them", and she continues that "an ambassador is someone who tells about their good experiences in Denmark to other people". As Simmons (2006) argues, if stories connect with audiences, then they may also impose their values and way of thinking on them. Hence, positive stories can engage and activate users to defend the brand. They are allies of VisitDenmark's preferred brand narrative and counter the users who co-destroy the message.

\section{Conclusion}

This research advanced on existing knowledge, which hitherto looked at co-destruction within product and service value (Plé, 2016; Smith, 2013; Vafeas et al., 2016). It instead examined the co-destruction of brand value where an amalgam of actors jointly undermine the preferred version of a destination brand, intentionally or unintentionally. While previous research examined mainly brand co-creation (Fournier and Avery 2011; Gensler et al. 2013; Singh and Sonnenburg 2012), this study departed from the binary interpretation of brand value processes and introduced the brand value continuum as a way to understand the dynamic, fluid multiple manifestations of brand value creation. Hence, by focusing on the brand of Copenhagen through the case of VisitDenmark, the paper demonstrated that there are varying degrees of codestructiveness and co-creativeness, which should be viewed along a storytelling spectrum.

The paper provided the empirical data to underscore Plé's (2016) assertions about the multi-facetted dynamical co-existence of co-creation and co-destruction, while also expanding it into the sphere of social media branding where brands are organic social processes (Iglesias et al. 2013) in which the politics of discursive counterpoints are prevalent as they are continually negotiated by multiple stakeholders. The findings also showed that value diminution (Vafeas et al. 2016) is a regular occurrence in destination branding on social media as brand co-destruction comes in various forms and intensity where some degree of value may still be achieved. What can be seen as destructive value for one stakeholder, can be seen as positive value for another stakeholder. Finally, even negative comments do not necessarily have negative consequences, as conversations about the brand contributes to a higher visibility and thus higher brand recognition, which challenges the co-destruction concept in terms of branding (see Nam et al. 2018; Swaleha et al. 2017), as even brand co-destruction can be 
viewed as value co-creation in terms of reach. Hence, examining the vignettes influencing the destination brand illustrates the complex multi-dimensional interplays and processes in which brand value is continually diluted, altered and generated in various forms and intensity by multiple stakeholders.

The paper also established that joint co-destruction of destination brands can be both intentional and unintentional. While users sometimes work together to jointly co-destroy (or co-create) the destination brand of Copenhagen, it is sometimes the algorithms of social media platforms as well as the interference of DMOs which generate an incidental artificial choreographing of joint co-destruction (or co-creation). The findings also showed that storytelling can both directly and indirectly counter co-destruction. Storytelling can directly entice users to defend the brand narrative, as the emotional connections created through storytelling persuades them to take action (Van Laer et al. 2014; Pera and Viglia 2016), while indirectly it can divert attention towards positive narratives. These findings are a major contribution to extant research as it reconceptualizes the dual terms of co-destruction and cocreation through the brand value continuum while expanding the study of service and product value processes into the sphere of brand value.

The managerial implication of these findings is significant and articulated in the form of four recommendations for DMOs. First, DMOs like VisitDenmark should repeatedly tell positive emotional narratives which entice uses to share further positive stories as part of a social experience, as it diverts attention away from destructive stories, while also encouraging users to acts as ambassadors defending the brand message. Storytelling is a collective cocreative process which generates a community identity. Second, the conceptualization of the brand value continuum visualizes the spectrum of brand value creation, and it illustrates how DMOs can accept some instances of brand value co-destruction in social media as they create brand awareness through reach. Hence, co-destructive stories can indirectly become cocreative value. Third, much content is merely neutral and not a threat to the preferred brand narrative. Hence, DMOs only need to focus on the purposively co-destructive content. Fourth, in collaboration with social media platforms, DMOs should further develop the ability to choreograph joint brand value co-creation, highlighting positive narratives while eliminating and hiding co-destructive content. In other industries, these insights are also useful in strengthening brand co-creation and diminishing co-destruction through storytelling. This paper thus provides practical contributions by offering functional tools to destination managers for countering brand co-destruction. 
This study had some limitations which creates a path for further research. While this paper focused on countering co-destruction of destination brands through storytelling, further research can also look at the benefits of more practical tools such as improving the service delivery and undertaking service recovery, which are part of what the DMO needs to do to improve the brand narratives in online social media spaces. Furthermore, it would be important to examine the dynamic multi-layered offline/online co-destruction tracing the continuing relationship between consumer and producers at various points during the service delivery and/or tourist experience. The focus on Facebook meant that we were likely to target an older demographic than we would have done if we had examined Instagram. Hence future research could be aimed at brand co-destruction on Instagram where more millennials are present. This may provide new insights into brand co-destruction.

While this paper specifically focused on destination brands, it is also important to examine the power of storytelling and the role of the brand value continuum within product and service brands. While the producer itself initially defines the identity of a product or service brand, the destination brand stems from multiple sources, where tourism marketing is just one of them (Morgan, Pritchard and Pride 2011). Hence, within product and service brands, other dynamics may surface. It is also worth investigating how users may undermine one aspect of the brand through their stories but may enforce other aspects of the same brand. Hence, codestructive and co-creative values are created within each user story. Furthermore, while a user story may co-destroy one brand, it may enforce another brand. Hence, a story's content is active at various points along the brand value continuum. Finally, further research should also study the politics of brand value creation, both in terms of the various stakeholders but also in terms of the wider societal issues involved in brand value creation.

\section{References}

Arksey, H., and P. T. Knight. 1999. “Achieving a Successful Interview”. In Interviewing for Social Scientists, edited by H. Arksey and P. T. Knight, 89-109. London: SAGE Publications, Ltd.

Ayres, L. 2008. "Thematic coding and analysis." In The sage encyclopaedia of qualitative research methods, edited by L. M. Given, 867-868. Thousand Oaks: Sage Publications Inc.

Banks, J., and M. Deuze. 2009. “Co-creative labour.” International Journal of Cultural Studies 12 (5): 419-431. 
Bierman, J. 2010. Tell me a story: storytelling to create impact brands. USA: Rare Design Ltd.

Brand Denmark. 2015a. "Brand Essence."

http://www.branddenmark.com/en/brand-essence/brand-essence (accessed November 14, 2015).

Brand Denmark. 2015b. "Position: Denmark's unique position." http://www.branddenmark.com/en/position/position (accessed November 14, 2015).

Constantino, T. E. 2008. "Constructivism." In The sage encyclopaedia of qualitative research methods, edited by L. M. Given, 116-120. Thousand Oaks: Sage Publications Inc.

Creswell, J. W. 1998. Qualitative inquiry and research design: choosing among five traditions. Thousand Oaks, Calif.: Sage Publications.

Denzin, N. K., and Y. S. Lincoln. 2011. "Introduction: The Discipline and Practice of qualitative research." In The sage handbook of qualitative research, edited by N. K. Denzin, N. K. and Y. S. Lincoln, 1-19. Thousand Oaks, California: Sage Publications Inc.

Dessart, L. 2018). "Do ads that tell a story always perform better? The role of character identification and character type in storytelling ads." International Journal of Research in Marketing 35 (2): 289-304.

Echeverri, P., and P. Skålén. 2011. "Co-creation and co-destruction: A practice-theory based study of interactive value formation.” Marketing Theory 11 (3):351-373.

Editorial board. 2019. "The dark side of regulating speech on Facebook." https://www.washingtonpost.com/opinions/the-dark-side-of-regulating-speech-onfacebook/2019/04/03/73316af4-557a-11e9-814fe2f46684196e_story.html?utm_term=.fd323035d8e8 (accessed July 28, 2019).

Flyvbjerg, B. 2011. "Case study." In The sage handbook of qualitative research, edited by N. K. Denzin, N. K. and Y. S. Lincoln, 301-316. Sage.

Fog, K., C. Budtz, and B. Yakaboylu. 2005. Storytelling: Branding in practice. Germany: Springer.

Fournier, S., and J. Avery. 2011. “The uninvited brand.” Business horizons 55:193 - 207.

Garrod, B., and A. Fyall. 2011. "The case study approach: wrongly maligned.” In Contemporary cases in tourism, edited by B. Garrod and A. Fyall, IX-XVI. Oxford: Goodfellow.

Gensler, S., F. Völckner, Y. Liu-Thompkins, and C. Wiertz. 2013. "Managing Brands in the Social Media Environment.” Journal of Interactive Marketing 27 (4):242-56.

Gössling, S. and I. Stavrinidi. 2015. "Social networking, mobilities, and the rise of liquid identities." Mobilities 11 (5):723-746. 
Guest, G., E. E. Namey, and M. L. Mitchel. 2013. Collecting qualitative data: A field manual for applied research. Thousand Oaks: Sage Publications, Inc.

Hays, S., S. J. Page, and D. Buhalis. 2013. "Social media as a destination marketing tool: its use by national tourism organisations." Current Issues in Tourism 16 (3):211-239.

Hanna, R., A. Rohm, and V. Crittenden. 2011. "We're all connected: The power of social media ecosystem.” Business Horizon 54:265-273.

Herskovitz, S. and M. Crystal. 2010. "The essential brand persona: storytelling and branding." Journal of Business Strategy 31 (3):21-28.

Hendricks, V. F. and Hansen, P. G. 2014. Infostorms: How to take information punches and save democracy. Switzerland: Springer International publishing.

Hollebeek, D.L. and T. Chen. 2014. "Exploring positively- versus negatively-valenced brand engagement: A conceptual model." Journal of Product and Brand Management 23 (1):62-74.

Hosany, S., G. Prayag, R. Van Der Veen, S. Huang, and S. Deesilatham, 2017. Mediating Effects of Place Attachment and Satisfaction on the Relationship between Tourists' Emotions and Intention to Recommend. Journal of Travel Research, 56(8), pp.1079-1093.

Iglesias, O., N. Ind, and M. Alfaro. 2013. "The organic view of the brand: A brand value cocreation model." Journal of Brand Management 20 (8):670-688.

Järvi, H., A. Kähkönen, and H. Torvinen. 2018. "When value co-creation fails: Reasons that lead to value co-destruction.” Scandinavian Journal of Management 34 (1):63-77.

Jin, A.S. 2012. "The potential of social media for luxury brand management." Marketing Intelligence and Planning 30 (7):687-699.

Kelner, M. 2018. "Nike's controversial Colin Kaepernick ad campaign its most divisive yet." https://www.theguardian.com/sport/2018/sep/04/nike-controversial-colin-kaepernickcampaign-divisive_ (accessed October 23, 2018).

Kim, J., and H Youn. 2017. "How to Design and Deliver Stories about Tourism Destinations." Journal of Travel Researc, 56 (6):808-820.

Kohli, C., S. Suri, and A. Kapoor. 2015. "Will social media kill branding?” Business Horizons 58 (1):35-44.

Kotler, P., D. H. Haider, I. and Rein. 1993. Marketing Places: Attracting Investment, Industry, and Tourism to Cities, States and Nations. New York: Free Press.

Kozinets, R.V. 2015. Netnography: Redefined. London: Sage.

Lincoln, Y. S. and E. G. Guba. 2013. The constructivist credo. California: Left Coast Press, Inc. 
Liu, H., L. Wu, and X. Li. 2019. "Social Media Envy: How Experience Sharing on Social Networking Sites Drives Millennials' Aspirational Tourism Consumption." Journal of Travel Research 58(3):355-369.

Lund, N.F., S. A. Cohen, and C. Scarles. 2018. "The power of social media storytelling in destination branding." Journal of Destination Marketing and Management 8:271-280.

Mak, A.H. 2017. "Online destination image: Comparing national tourism organisation's and tourists' perspectives.” Tourism Management 60:280-297.

Mangold, W.G. and D. J. Faulds. 2009. "Social Media: The New Hybrid Element of the Promotion Mix.” Business Horizons, 52 (4):357-65.

Martin, D. 2010. "Uncovering unconscious memories and myths for understanding international tourism behaviour.” Journal of Business Research 63:372-383.

Miller, J. L. Craighead, C. W., and Karwan, K. R. 2000. "Service Recovery: A Framework and Empirical Investigation." Journal of Operations Management 18 (4): 387-400.

Morgan, N., A. Pritchard, and R. Pride. 2011. "Tourism places, brand and reputation management", in Destination brands: Managing Place reputation (Third edition), edited by N. Morgan, A. Pritchard, R. Pride, 3 - 19. Oxford: Butterworth-Heinemann,

Munar, A.M. 2012. "Social media strategies and destination management." Scandinavian Journal of Hospitality and Tourism 12 (2):101 - 120.

Nam, K., J. Baker, N. Ahmad, and J. Goo. 2018. "Dissatisfaction, Disconfirmation, and Distrust: An Empirical Examination of Value Co-Destruction through Negative Electronic Word-of-Mouth (eWOM).” Information Systems Frontiers 1-18.

O’Reilly, K. 2009. Key concepts in Ethnography. London: Sage.

Parasuraman, A., Zeithaml, V. and Berry, L. 1985. "A Conceptual Model of Service Quality and Its Implications for Future Research." Journal of Marketing 49 (4): 41-50.

Pera, R. 2017. "Empowering the new traveller: storytelling as a co-creative behaviour in tourism." Current Issues in Tourism 20 (4):331-338.

Pera, R. and G. Viglia. 2016. "Exploring How Video Digital Storytelling Builds Relationship Experiences." Psychology \& Marketing 33 (12):1142-1150

Phillips, N., Hardy, C. 2002. Discourse Analysis. Thousand Oaks: Sage.

Plé, L. 2016. "Studying customers' resource integration by service employees in interactional value co-creation.” Journal of Services Marketing 30 (2):152-164.

Plé, L., and R. C. Cáceres. 2010. "Not always co-creation: introducing interactional codestruction of value in service-dominant logic." Journal of Services Marketing 24 (6):430437. 
Potter, J. 2008. "Discourse analysis." In The sage encyclopaedia of qualitative research methods, edited by L. M. Given, 217-220. Thousand Oaks: Sage.

Prahalad, C., and V. Ramaswamy. 2004. "Co-creating unique value with customers.” Strategy \& Leadership 32 (3):4-9.

Rahmani, K., J. Gnoth, and D. Mather. 2018. “Tourists' Participation on Web 2.0: A Corpus Linguistic Analysis of Experiences.” Journal of Travel Research 57 (8):1108-1120.

Roser, T., A. Samson, P. Humphreys, and E. Cruz-Valdivieso, E. 2009. Co-Creation: New Pathways to Value: An Overview. London: Promise \& LSE Enterprise.

Saunders, M. N. K. 2012. “Choosing research participants.” In The Practice of Qualitative Organizational Research: Core Methods and Current Challenges, Edited by G. Symon and C. Cassell, 37-55. London: Sage.

Scarles C. 2009. "Becoming tourist: renegotiating the visual in the tourist experience." Environment and Planning D 27 (3):465-488.

Simmons, A. 2006. The story factor: Secrets of influence through the art of storytelling. New York: Basic Books.

Singh, S. and S. Sonnenburg. 2012. "Brand performances in social media." Journal of interactive marketing 26:189-197.

Smith, A.M. 2013. "The value co-destruction process: a customer resource perspective." European Journal of Marketing 47 (11/12): 1889-1909.

Statista. 2019. "Number of monthly active Facebook users worldwide as of 2nd quarter 2019 (in millions)." https://www.statista.com/statistics/264810/number-of-monthly-activefacebook-users-worldwide/ (accessed July 28, 2019).

Swaleha, P., M. Samy, and B. Jones. 2017. "Facebook: a blessing or a curse for grocery stores?” International Journal of Retail \& Distribution Management 45 (12):1242-1259.

Tussyadiah, I. and D. Fesenmaier. 2008. "Marketing places through first-person stories - an analysis of Pennsylvania Roadtripper blog." Journal of Travel \& Tourism Marketing 25 (34):299-311.

TripAdvisor 2018a. Annual Report. USA: TripAdvisor.

TripAdvisor 2018b. C'hristiania." https://www.tripadvisor.com/Attraction_Review-g189541d259687-Reviews-Christiania-Copenhagen_Zealand.html (accessed November 4, 2018).

Usakli, A., B. Koç, B. and S. Sönmez. 2017. "How 'social' are destinations? Examining European DMO social media usage." Journal of Destination Marketing and Management 6 (2):136-149.

Vafeas, M., T. Hughes, and T. Hilton. 2016. "Antecedents to value diminution.” Marketing Theory 16 (4):469-491. 
Vallaster, C., S. Von Wallpach, and S. Zenker. 2018. "The interplay between urban policies and grassroots city brand co-creation and co-destruction during the refugee crisis: Insights from the city brand Munich (Germany)." Cities 80:53-60.

Van Laer, T., S. Feiereisen, and L. M. Visconti. 2019. "Storytelling in the digital era: A metaanalysis of relevant moderators of the narrative transportation effect." Journal of Business Research 96:135-146.

Van Laer, T., K. De Ruyter, L. M. Visconti, and M. Wetzels. 2014. "The extended transportation-imagery model: A meta-analysis of the antecedents and consequences of consumers' narrative transportation.” Journal of Consumer Research 40 (5):797-817.

Velji, J. 2017. "21 Game-Changing Social Media Trends in 2017."

https://buildfire.com/social-media-trends-2017/ (accessed June 12, 2017).

VisitDenmark 2014. "Turistens Digitale Rejse."

http://www.visitdenmark.dk/da/danmark/turistens-digitale-rejse (accessed October 13, 2015).

Visitdenmark 2015a. "Historien om VisitDenmark."

http://www.visitdenmark.dk/da/danmark/historien-om-visitdenmark (accessed October 13, 2015).

VisitDenmark 2015b. "Strategi for Storby 2016."

http://www.visitdenmark.dk/da/danmark/strategi-storby-2016 (accessed October 15, 2015).

VisitDenmark 2016a. "Christiania."

http://www.visitdenmark.com/copenhagen/attractions/christiania?utm_source=Facebook\&ut m_medium=fb-wallpost\&utm_campaign=wallpost (accessed June 6, 2016).

VisitDenmark 2016b. "Tivoli Gardens: Let loose at Copenhagen's famous fairground!" http://www.visitdenmark.com/copenhagen/attractions/tivoli-gardens (accessed June 14, 2016).

VisitDenmark 2018a. "Christiania."

https://www.visitdenmark.dk/da/kobenhavn/attraktioner/christiania (accessed October 30, 2018).

VisitDenmark 2018b. "Christiania."

Rhttps://www.visitdenmark.dk/da/copenhagen/attractions/christiania (accessed October 30, 2018).

Woodside, A.G. 2010. "Brand-Consumer Storytelling Theory and Research: Introduction to a Psychology \& Marketing Special Issue.” Psychology and Marketing 27 (6):531-540.

Yin, R. K. 2013. Case study research: design and methods ( $5^{\text {th }}$ edition). California, USA: Sage Inc. 